\title{
The homeobox in vertebrate development
}

\author{
M.D. Goulding and P. Gruss \\ Max-Planck-Institut für Biophysikalische Chemie, Göttingen, Federal Republic of Germany \\ Current Opinion in Cell Biology 1989, 1:1088-1093
}

\section{Introduction}

Embryonic development is regulated by a co-ordinated programme of intra- and inter-cellular signals which combine to shape the final body. Each organism contains within its genome a developmental programme allowing the faithful reproduction of the species. It is known that many of the cellular processes involved in organizing the embryo are conserved amongst vertebrates, suggesting that widely divergent species may share similar strategies for pattern development. One genetic element underpinning these strategies may be the homeobox, a conserved regulatory domain that encodes a 60 -amino acid helixcontaining motif [1] originally found in many Drosopbila genes which control pattern development. Consequently, the identification of similar motifs in higher animals leads to the belief that the homeobox may also be an important regulatory domain for vertebrate development. The evidence implicating homeobox-containing genes in pattern formation in vertebrates, while still preliminary, is clearly consistent with this role.

\section{Homeoboxes as development determinants}

A number of vertebrate Hox genes have been isolated and their expression during embryogenesis characterized. While many of the Antennapaedia-type homeobox genes are expressed in the central nervous system (CNS) and in mesodermal structures of the mouse embryo, each gene has a unique region of expression that partially overlaps the expression region of other homeobox-containing genes. The overlapping expression of these genes in the neural tube and adjacent mesoderm may indicate a combined action in these tissues.

Homeobox-containing genes may regulate pattern development in the vertebrate embryo in the following ways:

(1) Homeobox-containing genes may direct specific cellular differentiation programmes within a discrete tissue in the developing embryo. Hence, they would act directly in concert with other genes in processes such as organogenesis.

(2) The overlapping of expression in a particular region of the embryo may provide information on positron, possibly co-ordinating the fates of different cell types within a defined region. For ex- ample, a particular pattern of gene expression might inform a cell of its position in the em. bryo or ensure migrating cells find their correct targets. Obviously, the overlapping expression of a small number of these genes would provide a very precise set of position determinants.

The fact that some Hox genes are also specifically expressed in certain adult tissues indicates a possible role in cellular differentiation. For example, the expression of the murine homologue of the caudal gene $(C d x-1)$ in the mouse embryo is consistent with a role in cell differentiation rather than determination of position. $C d x-1$ is expressed primarily late in murine embryogenesis and in the adult. Moreover, expression of $C d x-1$ is restricted to the epithelium of the large intestine during formation of the intestinal villi [2]. A role in differentiation is also consistent with $C d x-1$ expression in adult gut epithelium because of the continual proliferation and differentiation of gut epithelia that occurs in the adult. The next step in analysing the role of $c d x-1$ will be to determine whether it is expressed in stem cells or in one of the four types of differentiated epithelium found in the intestine.

The expression pattern of the mouse engrailed gene En-2 suggests a role in both localization and cellular differentiation. The mouse $E n-2$ gene contains a homeobox of the engrailed-type and is expressed from early embryogenesis throughout development into adulthood [3]. In the 8-12 day embryo, En-2 is expressed in a band of neural tissue in the metencephelon, and subsequently in the structures derived from this region, namely, the developing cerebellum, pons, periaqueductal gray and collicoli. In the neonate and adult strong expression of $\mathrm{En} \cdot 2$ is still observed in the granule layer of the cerebellum and in the pons. While the region-specific expression of $\mathrm{En}-2$ in the early mouse embryo suggests that it has a role in delineating a specific subdomain in the neural tube and brain, later expression in the cerebellum of the neonate may reflect an alternative role in cell differentiation. Interestingly, the restricted regional expression of the $E n-2$ gene at the junction of the hindbrain and midbrain has also been conserved in zebra fish (Njolstad and Fjose, Biocbem Bioplys Res Commun 1988, 157:426-432) and in the chick [4].

The expression of the Antptype homeobox-containing genes in vertebrates indicates that they may have a

Abbreviations

Cdx-1—caudal homeobox gene; CNS-central nervous system; mRNA-messenger RNA; OTF-octamer-transcription factor. 


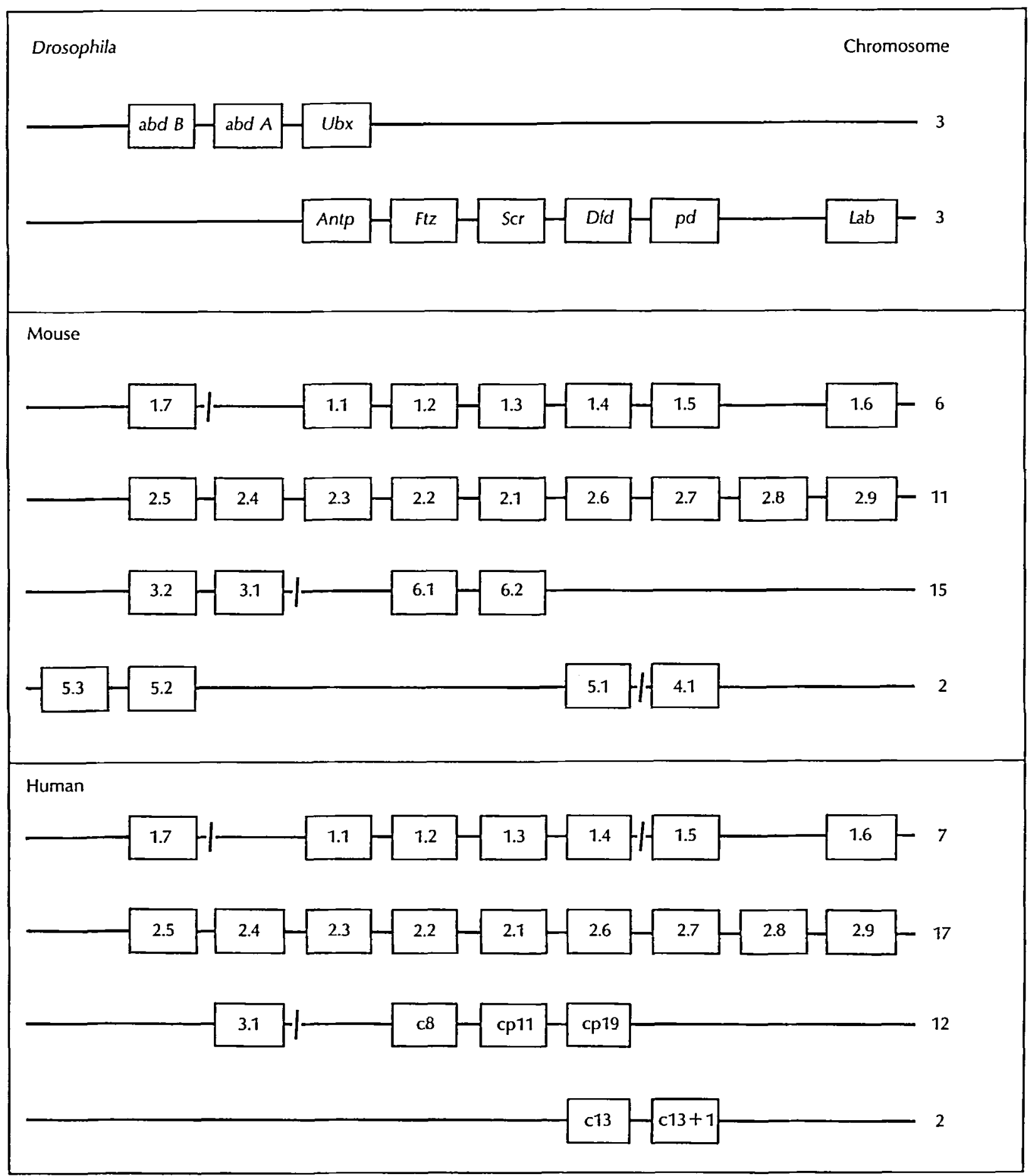

Fig. 1. Structure of the homeotic gene and Hox gene loci in Drosphila, mouse and human. Genes that have been identified in each cluster are aligned according to position in the locus and with those members of the other loci sharing the greatest homology. Reproduced with the kind permission of $\operatorname{Dr} M$. Kesse.

role in determining region-specific events. In the mouse and human genome, four clusters of the Antp-class of homeobox-containing genes have been identified [5-8]. Recently, attention has been drawn to the fact that within these vertebrate Hox-gene clusters each gene shares con- siderable homology with its putative Drosopbila counterpart on chromosome 3 (reviewed in [9], see also Fig. 1). Furthermore, in Drosopbila, the arrangement of lab $p d$ $D F d-S c r-A n t p-U b x$-abd $A-a b d B$ genes on chromosome 3 parallels their anterior-posterior sequence of expres- 
sion in the Drasopbila embryo. It now appears that genes within the Hox-gene clusters of the mouse show a sim. lar relationship. Thus the nearer to the $3^{\prime}$ end a gene is in a cluster, the more anterior its border of expression is in the developing embryo. For example, in the murine $H o x-2$ cluster, $\operatorname{Hox} 2.7$ is expressed in hindbrain regions, while the anterior borders of $\operatorname{Hax} 2.4$ and $H o x 2.5 \mathrm{ex}$ pression extend only to the cervical region of the CNS [7]. This relationship also holds for the Hox 5 cluster [8]. Hox 5.2 and Hox 5.3 are expressed in the lower thoracic and lumbar regions of the neural tube with the border of $\operatorname{Hox} 5.2$ being slightly anterior to that of Hox 5.3. In contrast, $H o x$ 5.1, which occupies a more $3^{\prime}$ position in the cluster, is expressed in the neural tube as far forward as the myelencephalon [10]. These results support the argument that the vertebrate $A n t p$ type homeobox-clusters and their Drosopbila counterparts are derived from a common ancestral locus. Furthermore, the arrangement of the Hox gene clusters and their concomitant overlapping pattern of expression seems to have been conserved as a mechanism for determining position along the rostral-caudal axis of the vertebrate embryo.

The expression of many Hox genes in the neural tube and adjacent mesoderm of vertebrates is not surprising, since the general body plan of vertebrates would appear to necessitate co-ordination of positional cues between these tissues. One gene that is expressed with similar boundaries in neural and mesodermal tissue is the Xeno pus XI Hbax 1 gene whose expression is confined within a narrow anterior-posterior band [11]. Expression is restricted to neuroectoderm and mesodermal tissue with the same anterior and posterior boundaries. De Robertis et al. [12] argue that at the early neurala stage of Xenopus the position of mesoderm is determined and can induce similar positional cues in the adjacent neuroectoderm. This process, termed 'homeogenetic induction', may be a mechanism for co-ordinating positional signals in different tissues within the embryo. In contrast to Xenoptus, there is little evidence for homeogenetic induction in the mouse. While expression of the Hox 1.5 gene in the neuroepithelium and mesoderm is in close register in the early mouse embryo (Gaunt, Development 1987, 102:51-60), expression of the endogenous Hox 1.1 gene and a transgene containing lac $Z$ under the control of $\operatorname{Hox} 1.1$ regulatory sequences are not in register 7-9 days post-coitus (Dressler and Püschel, personal communication). Certainly, later in embryogenesis, nearly all the known Hox genes are clearly expressed 'out of register' in these two tissues.

Pax 3, a new member of the paired-type homeobox gene family has been identified and its expression suggests that it may regulate morphogenetic gradients along the ventral-dorsal axis of the embryo. Analysis of $\mathrm{Pax}=3$ in the developing neural tube shows that it is expressed in the neuroepithelium only in the dorsal half of the neural tube. Restriction of Pax-3 transcripts to those neuronal progenitor cells along the entire dorsal half of the neural tube raises the possibility that $\operatorname{Pax}-3$ plays a role in dividing the CNS into sensory and motor compartments (Goulding et al., unpublished observations).
The development of extremities such as the limb requires a unique set of positional determinants, some of which may be shared by body and limb alike, whilst others might be region specific. Homeobox-containing genes are among the potential candidates for regulating posi tional cues in the developing limb. In Xenopus and mice, the homologue of the human Hox 5.2 gene is expressed in all four limb buds as a gradient as well as in caudal regions of the neural tube and somitic mesoderm. Maximal expression of Hox 5.2 is observed in the distal and posterior mesenchyme of the limb bud in contrast with $X 1$ Hbox 1 which is expressed only in the anterior mesenchyme of the forelimb [13]. The Hox 7.1 gene shows a more limited pattern of expression in the mouse. In $121 / 2$-day embryos, Hox 7.1 is expressed predominantly in the most distal region of the limb bud, but also in the maxillary and mandibular processes that are derived in part from neural crest cells $[14,15]$. Interestingly, Hox 7.1 expression is restricted to neural crest cells prior to and during neural tube closure. Whether Hox 7.1 acts to influence the fate of these neural crest cells needs to be clarified. The fact that $\operatorname{Hox} 1.1, X 1 \operatorname{Hbox} 1, \operatorname{Hox} 5.2$ and Hox 7.1 are all expressed in characteristic gradients during limb bud formation may be indicative of an involvement in processes that polarize the limb bud. It may be now possible, by manipulating their expression pattem in limb bud cultures, to test whether these genes act as morphogenetic gradients in the limb.

\section{Functional analysis of homeobox genes in the vertebrate}

In Drosophila the functional analysis of homeobox-containing genes in pattern formation has been greatly facilitated by the plethora of genetic mutants available. With the advent of molecular biology many of these mutants have been identified and characterized. Data from genetic analyses of the Hox genes in vertebrates are limited and as a result their exact role in vertebrate development remains unclear.

Altering the normal morphogenetic gradients by over-expression of Hox genes at ectopic sites in the embryo is one approach to testing their role during embryogenesis. Such studies may resolve the question of whether the observed patterns of Hoxgene expression impart positional information to the developing embryo.

In Xenopus the functions of two homeobox-containing genes have been analysed by injecting synthetic messenger RNA (mRNA) encoding them into Xenopus embryos. Using this approach, it has been shown that over-expression of the $X b \circ x-1 A$ gene, which is expressed predominantly in the somitic mesoderm, can disrupt somitogenesis. In particular, over-expression of $X b o x-1 A$ resulted in dysplasia of somitic muscle tissue with the consequent loss of the metameric pattern of muscle bundles adjacent to the neural tube. The differentiation of somitic mesoderm into muscle cells was not grossly altered, but the myotome on the affected side of the embryo appeared to be incorrectly orientated on the anterior-posterior axis. This supports the argument that $X b a x-1 A$ acts as a posi- 
tional signal during somitogenesis rather than a differentiation signal [16].

A second Xenopus homeobox-containing gene has also been analysed using this approach. $X b o x-3$ is particularly interesting, since there is a gradient of expression of $X 70 x \cdot 3$ along the anterior-posterior axis of the Xeno pus embryo. This means that it is probable that $X 30 x-3$ has a role in positional determination. Injecting Xhox-3 mRNA into prospective anterior regions of the early embryo resulted in alterations to the normal gradient of $X b \circ \times 3 \mathrm{mRNA}$ during gastrulation and neuralation. The anterior region, which normally has a low level of $X b o x-3$ mRNA, had morphological defects in embryos injected with $X b o x-3$ [17]. Interestingly, the phenotype observed with $X b 0 x-3$ over-expression mimicked the defects caused by treatments that prevent prospective anterior mesodermal cells from migrating to their correct position during gastrulation. Both these studies support the theory that Hox genes act as positional determinants for mesodermal cells during Xenopus development.

The roles of two developmentally regulated homeoboxcontaining genes have also been analysed in mice by causing over-expression during embryogenesis. In one study, the murine Hox 1.4 gene was over-expressed in transgenic animals by introducing multiple copies of it under the control of its putative endogenous promoter [18]. Although very little expression of the transgene was detected in testes, which normally express Hox 1.4, there were elevated levels of the transgenic mRNA with the correct spatial distribution in the CNS and lung. More importantly, a high level of Hox $1.4 \mathrm{mRNA}$ was observed in the gut mesenchyme, a site where no expression of $\operatorname{Hox} 1.4$ had been detected previously. The consequence of the over-expression of Hox 1.4 in the gut mesenchyme was that newborn mice developed a fatal condition known as congenital megacolon. Previously congenital megacolon has been associated with a severe deficiency in myenteric ganglia, neural crest derivatives that migrate into the gut mesenchyme. It is, therefore, possible that over-expression of Hox 1.4 in these mice interferes with the positional signals that normally guide the neural crest progenitors of myenteric ganglia to their target. This would suggest that $H o x$ gene expression may act as a positional cue for migrating neural crest cells.

Neural crest cells also appear to be a target for ectopic expression of the Hox 1.1 gene in transgenic mice. When ubiquitous expression of the Hox 1.1 gene in mice was achieved using the $\beta$-actin gene promoter, a number of abnormalities were found in newborn transgenic mice, i.e. cleft palate and non-fused pinnae (Balling et al., Cell 1989, 58:337-347).

It should be noted that the mesenchyme tissue that contributes to all the affected structures in these transgenic mice is derived at least in part from first arch neural crest cells. Morphological abnormalities in structure derived from the occipital somites are also observed in these mice (Kessel, unpublished results). This may be a consequence of ectopic expression of $\operatorname{Hox} 1.1$ in the anterior somitic mesoderm and the subsequent alteration of the normal morphogenetic gradients in this region. The evidence to date is consistent with a role for homeoboxcontaining genes as positional determinants in the vertebrate embryo. Not only are they expressed in restricted patterns during embryogenesis, but altering these patterns of expression also has severe effects on development.

Loss of gene function by homologous recombination to inactivate a particular gene is an alternative approach to the study of the function of homeobox-containing genes in development (Thomas and Capecchi, Cell 1987, 51:503-512). While much progress has been made in developing these potentially powerful techniques, germ line transmission still remains a problem $[19,20]$.

\section{Homeoboxes are transcriptional factors in vertebrates}

Recently, homeodomains have been identified in known eukaryotic transcription factors. The ubiquitous octamertranscription factor (OTF)-1 and the $B$ cell specific OTF-2 each contain a functional homeobox domain [21-24]. Both $O T F-1$ and $O T F-2$ bind to a conserved octamer motif (ATGCAAAT) present in a variety of promoter/enhancer regions. The homeodomains in OTF-2 and $O T F-1$ are part of a larger conserved region known as the POU domain. While the homeodomain in each of these transcriptional factors is only distantly related to the Antp-type homeodomain, the OTF-1 and OTF-2 proteins share a high degree of homology (87\%) over the entire POU domain. At present, it is unclear exactly how the POU box works in these proteins, although, at least in the case of OTF-1, it is important in DNA binding [25]. In other homeobox-containing proteins, the homeodomain appears to be sufficient for DNA binding. Two other proteins, unc- 86 and $\mathrm{Pit}-1$ or growth hormone factor-1, also contain the POU domain [26-28]. The function of unc-86 is in development in Caenorbabditis ele gans to regulate neuronal cell differentiation, while Pit1 is a rat-pituitary-specific transcriptional factor, regulating transcription in lactotrophic and somatotrophic cell types. It is possible that Pit-1 acts in these cell types to regulate certain aspects of their development, since expression of Pit- 1 is seen in the rat brain during embryogenesis [29]. OTF-2 is also expressed in the complete CNS during embryogenesis [29] (Hatzopoulos et al., unpublished observations) with high levels in the diencephalon at 12 days post-coitus as well as in discrete regions of the adult brain. A family of octamer-specific binding factors has been identified in the mouse embryo (Scholer et al., EMBO J 1989, 8:2543-2550), and their characterization will yield further insights into the mechanism of homeobox action during development. At present, structural analysis of the homeodomain only strengthens the conclusion that the homeobox is an integral part of these transcriptional regulators. When the predicted consensus structure for a number of known homeobox domains is analysed, it shows striking structural homology with the $\lambda$-repressor protein (Tsonis et al., Biochem Bioply's Res Commun 1988, 157:100-105) [30]. These structure predictions indicate that the homeodomain forms three $\alpha$ helices, very similar to bacterial repressor molecules. 
The circle has closed, but with a small twist. While it is clear that the homeobox is a functional domain in transcription factors, not all these transcription factors are cell-type specific. For a while we believed that the homeobox might be a unique motif encoded by developmental control genes. Rather the reverse now appears to be true: the homeobox is a conserved protein domain that has been used to good effect by a number of pro. teins to regulate development.

\section{Conclusions and future prospects}

Many gaps remain in our knowledge of how homeoboxcontaining proteins act during development. Clearly, we are dealing with a complex group of transcriptional regulatory proteins; however, it remains to be determined how they function in embryonic development. Analysis of their role in development will require not only a mechanistic approach to their mode of action, but also an understanding of how they interact with and influence the biological processes that shape the embryo. The structural similarity of the homeodomain to the $\alpha$-helical motifs in the $\lambda$ repressor and cro proteins provides an important clue to how homeo-proteins might work. It is well known that in $\lambda$ phage, cro and the $\lambda$ repressor (cI) play a pivotal role in executing the lysis-lysogeny decision by acting as a transcriptional switch mechanism. The subsequent transcriptional activation or repression of early lytic genes determines the growth pathway $\lambda$ will follow. It is noteworthy that many of the Drosopbila homeodomain proteins activate or repress transcription of potential candidate genes $[31,32]$, although it is unclear whether these observations can be extrapolated to vertebrates. Nevertheless, if homeodomain proteins are important components of transcriptional switching in vertebrates, then the $\lambda$ model allows us to understand how differing local concentrations of homeodomain proteins might activate or repress the transcription of their developmental target genes.

\section{Acknowledgements}

We wish to thank Dr A. Hatzopoulos for his incisive comments on this review.

\section{Annotated references and recommended reading}

- Of interest

$\bullet \quad$ Of outstanding interest

1. OtTING G, QLAN Y, MOUer M, AfFolter M, Gerrivg W,

- WUTHRICH K: Secondary structure determination for the Antennapedia homeodomain by nuclear magnetic resonance and evidence for a helix-tum-helix motif. $E M B O J$ $1988,7: 4305-4309$

Structural analysis of a 68-amino acid homeodomain peptide and the deduced protein backbone structure.

2. DUPREY P, ChOWDHURY K, DRESSLER GR, BAHNG R, SHON D,

- GUENET J-L, GRUSS P: A mouse gene homologous to the Drosopbila gene caudal is expressed in epithelial cells from the embryonic intestine. Genes Dev 1988, 2:1647-1655.
Study describing isolation, sequence and pattem of expression of the mouse homologue of caudal gene. Expression is restricted to the in testinal epithelia.

3. DAVIS CA, NOBLE-TOPHAM SE, ROSSANT J, JOYNER AL: Expres- sion of the homeobox-containing gene En-2 delineates a specific region of the developing mouse brain. Genes Dev 1988, 2:361-371.

Details the restricted pattern of En-2 expression in the mouse meten cephalon and derived structures.

4. GardNer CA, DARNEL DK, POOLE SJ, ORDAHL CP, Barald KF:

- Expression of an engrailed-like gene during development of the earlly embryonic chick nervous system. I Neurasci Res 1988, $21: 426-437$.

Identification of the chick engrailed gene. Both engrailed transcripts and protein are localized to the hindbrain-midbrain junction in 2-day-old chick embryos.

5. Bonclieni E, SOMMa R, Acampora D, PANNESE M, D-EspostTo - M, Fafella A, SLIEONe A. Organization of human homeobox genes. Hum Reprod 1988, 3:880-886.

The chromosomal organization of the human homeobox genes is de scribed and compared with other known $H o x$ gene clusters.

6. GAUNT SJ, SHARPE PT, DUBOULE D: Spatially restricted - domains of homeo-gene transcripts in mouse embryos: relation to a segmented body plan. Development 1988 104:169-180.

The anterior-posterior limits of gene expression for genes from the Hax 1 cluster, $\operatorname{Hax} 3.1$ and $\operatorname{Hax} 61$ were determined in the mouse embro. Relationship between the position of a gene in the gene complex and expression along the anterior-posterior axis is discussed.

7. GrahaM A, Papalopulu N, KRUMIAUF R: The murine and - Drosophila homeobox gene complexes have common features of organization and expression. Cell 1989, 57:367-378. The expression of 7 genes from the $H a x 2$ cluster were anabsed by in situ hytridization in the neural tube, somites and lung. Their position in the cluster was then compared with the anterior border of expression.

8. DUBOULE D, DOUE: The structural and functional organi- zation of the murine hox gene family resembles that of Drosophila homeotic genes. EIIBO J 1989, 8:1497-1505. Compares the expression pattern of $\operatorname{Hax} 1.6,5.2$ and 5.3 with their position in the murine Hax gene clusters. Comparison also with the Drosophila homeotic cluster on chromosome 3.

9. AKAM M: Hox and HOM: homologous gene clusters in - insects and vertebrates. Cell 1989, 57:347-349.

An excellent review comparing the Drasophila antennapaedia complex and ultrabithorax complex with their putative murine homologues.

10. Featherstone MS, Baron a, Gaunt SJ, Mattei MG, Duboule

- D: Hox-5.1 defines a homeobox-containing gene locus on mouse chromosome 2. Proc Natl Acad SCi USA 1988, 85:4760-4764.

Mapping, sequence and in situ hybridization of the Hax 5.1 gene, the first of a new mouse homeobox cluster on chromosome 2. Expressed in neural tube, somitic mesoderm and testes.

11. OUNer G, Wright CVE, Harowicke J, DE Robertis EM: Dif- ferential anterior-posterior expression of two proteins en coded by a homeobox gene in Xenopus and mouse embryos. EMIBO J 1988, 7:3199-3210.

The expression of the Xenopus X1 Hbax 1 gene is described in mouse and Xenopus In Xenopus the gene is expressed in a discrete band of tissue along the anterior-posterior axis in neuroectoderm and mesoderm.

12. DE ROBERTIS EM, OLVER G, WRGHT CVE: Determination of - axial polarity in the vertebrate embryo: homeodomain proteins and homeogenetic induction. Cell 1989, 57:189-191. In this review the concept of homeogenetic induction is described as a possible model for regional induction of genes in different tissue types.

13. OINFr G, Sidell N, Fiske W, heinzManN C, Mohaidas T,

- SPARKES RS, DE Robertis EM: Complementary homeo protein gradients in developing limb buds. Genes Dev 1989, 3:6 $11-650$.

Localization of Hox 5.2 and X1 Hbox 1 proteins in vertebrate limb buds. The study shows that these 2 proteins show opposing gradients of expression in the vertebrate limb bud.

14. HIL RE, JONES PF, REES AR, SUIE CM, JUSTICE MJ, COPELAND - NG, JenktNs NA, Gratial E, DAVIDSON DR. A new family of mouse homeo box-containing genes: molecular struc- 

ture, chromosomal location, and developmental expression
of Hox-7.1. Genes Dev 1989, 3:26-37. One of 2 papers analysing the first member of a new class of vertebrate homeobox-containing genes that contain a homeodomain of the muscle segment homeobox type.

15. Robert B, Sassoon D, JacQ B, Gehrivg W, Buckingham M: - Hox.7, a mouse homeobox gene with a novel pattern of expression during embryogenesis. EMBBO J 1989, 8:91-100.

The complementary paper to that by Hill et al [14] describing the sequence, chromosomal localization and expression pattern of Hox:7 (7.1). Expression is found in facial structures, nostral neural crest and limb buds.

16. HARVEY RP, Melton DA: Microinjection of synthetic Xhox-

- IA homeobox mRNA disrupts somite formation in developing Xenopus embryos. Cell 1988, 53:687-697.

This study indicates that $X h \circ \times 1 A$ may regulate aspects of somitogenesis in Xenoptus embryos. Unfortunately, good expression data for the endogenous gene could not be obtained.

17. Ruz I AltaBa A MelTon DA. Involvement of the Xeno -. pus homeobox gene Xhox 3 in pattem formation along the anterior-posterior axis. Cell 1989, 57:317-326.

An excellent study showing that disrupting the normal gradient of $X 7 \mathrm{xax}$ 3 during gastrulation and neuralation in Xenopus disrupts the later development of anterior regions.

18. WOLGENUTH DJ, BeHRNGer RR, MOSTOUER MP, BRINSTER - RL, Paumiter RD: (Letter to the Editor) Transgenic mice overexpressing the mouse homoeobox-containing gene Hox-1.4 exhibit abnormal gut development. Nature 1989 , $337: 464-467$.

This study shows that over-expression of $\operatorname{Hax} 1.4$ in the mouse intes tine results in a disorder displaying a similar pathology to congenital megacolon. Possible neural crest invokement is discussed.

19. ZMMMR A, Gruss P: (Letter to the Editor) Production of - chimaeric mice containing embronic stem (ES) cells carring a homoeobox Hox 1.1 allele mutated by homologous recombination. Nature 1989, 338:150-153.

Describes the introduction of a mutation into 1 allele of the Hox 1.1 gene. By microinjecting ES cells, a high frequency of homologous recombination was achieved.

20. JOYNER AL, SKARNES WC, ROSSANT J: (Letter to the Editor)

- Production of a mutation in mouse En-2 gene by homologous recombination in embryonic stem cells. Nature 1989 , 338:153-156.

This paper describes the use of the neomycon gene as an insertional mutant and selection gene. A high frequency of homologous recombination was also obtained in this study.

21. STURM RA, DAS G, HERR W: The ubiquitous octamer-binding - protein Oct-1 contains a POU domain with a homeobox subdomain. Genes Dev 1988, 2:1582-1599.

Isolation and characterization of the Oct-1 gene and identification of a highly conserved sequence encoding a homeodomain.

22. KO HS, FAST P, MCBRIDE W, STAUDT LM: A human protein - specific for the immunoglobulin octamer DNA motif contains a functional homeobox domain. Cell 1988, 55:135-144 Isolation of the human B cell specific Oct. 2 complementary DNA and identifeation of a homeodomain.

23. SCHFDeret C, Cromush JA, Gerster $T$, Kat'akali $K$, - BALMACEDA C.G, CURRIE RA, ROEDER RG: A human lymphoidspecific transcription factor that activates immunoglobulin
genes is a homoeobox protein. Nature 1988, 336:551-556. This paper describes the isolation of the OTF 2 gene. The function of the gene product was analysed by gelshift assays and footprinting.

24. ClerC RG, CORCORAN LM, LeBowtTZ JH, BatLMORE D, SHaRP - PA: The B-cell-specific Oct-2 protein contains POU box and homeobox-type domains. Genes Dev 1988, 2:1570-1581. A further paper describing the isolation of an Oct-2 encoding complementary DNA.

25. STURMER RA, HERR W: The POU domain is a bipartite DNA. binding structure. Nature 1988, 336:601-604.

Analysis of the POU domain by gelshift retardation essays showing that the POU-specific box is involved in sit-specific binding.

26. BODNER M, CASTRUO J L, THEIU LE, DeERLNCK T, EUSMAN M, - KarL M: The pituitary-specific transcription factor GHF-1 is a homeobox-containing protein. Cell 1988, 55:505-518. Describes the isolation of the gene encoding the gronth-hormone transcription factor present in the pituitary. Sequence analysis reveals a POU domain containing a homeobox.

27. LNGRAHAM HA, CiIEN R, MLANGaLAM HJ, ElSHOLtz HP, FLYNN SE - IN CR, SLMmons DM, SwaNson L, ROSENfEID MG: A tissuespecific transcription factor containing a homeodomain specifies a pituitary phenotype. Cell 1988, 55:519-529.

Describes the isolation of the piruitary-specific transcription factor Pit-1 for the transcription of the rat prolactin gene. The gene is analogous to gronth hormone transcription factor-1 and contains a POU domain.

28. FNAEY M, RUVKUN G, HORVIIZ HR. The $C$. elegans cell tin-

- $\quad$ eage and differentiation gene unc-86 encodes a protein with a homeodomain and extended similarity to transcrip. tion factors. Cell 1988, 55:757-769.

Nematodes containing mutations in unc-86 have developmental defects affecting the nerous system. Cloning of the unc-86 loci, identification of the gene and sequence analysis show the presence of a POU domain.

29. HE X, Treacy MiN, Shmons dM, IngralaM HA, Swanson LW, - ROSENFIELD MG: Expression of a large family of POU domain regulatory proteins in mammalian brain development. Nature $1989,340: 35-42$

The expression of Pit-1 and Oct-2 is anałysed during embryogenesis and in the adult rat brain. The results show expression in the embryonic CNS and regions that will later give rise to expressing structures in the brain.

30. Garcia-Blanco Ma, Clerc RG, Sharp Pa: The DNA-binding - homeo domain of the Oct-2 protein. Genes and Dev 1998, 3:739-745.

Structural analysis of the homeodomain of Oct.2 and comparison of the sequence-predicted structure with bacterial repressors whose 3-dimensional structures are already known.

31. JAYNES JB, O'FARRELL PH: Activation and expression of - transcription by homeodomain-containing proteins that bind a common site. Nalure 1988, 336:744-749.

This sudy shows that the $\mathrm{ftz}$ homeodomain protein can activate transcription from a consensus homeobox binding site, whereas the en and eve proteins bound to this site repress transcription.

32. Hav K, LEVLVE MS, MLNELY JL: Synergistic activation and - repression of transcription by Drosopbila homeobox proteins. Cell 1989, 56:573-583.

In this study the effects of homeobox proteins on transcription are anal. ysed using an upstream regulatory element from the engrailed gene. Dif ferent homeobox-t)pe proteins bind this element to either sumulate or repress transcription from the adjoining promoter. 